\title{
Assessment and diagnosis of insomnia for clinical and research practice: a scoping review protocol
}

\author{
Avaliação e diagnóstico de insônia para práticas clínica e de pesquisa: protocolo de revisão de \\ escopo
}

Evaluación y diagnóstico del insomnio para las practicas clínica y de investigación: un protocolo de scoping review

\begin{abstract}
Insomnia is one of the leading sleep disorders, affecting different age groups, influencing individual's ability to perform daily life activities, and ultimately diminishing their quality of life. This scoping review aims to identify instruments applied for the diagnosis of insomnia in clinical and research settings to support the nursing process and the decision-making. This review is based on the scope review framework proposed by Peters et al. (2020). The research strategy outlined aims to find studies published in the CINAHL (EBSCOhost) electronic database, Scopus, PubMed and WoS Portals. Grey literature will be accessed through free search via Google and Google Scholar, CAPES Thesis Repository, the Organizations Sleep Brazilian Association and World Sleep Society. This scope review is expected to assist nurses in the clinical reasoning process for identifying Nursing Diagnosis "insomnia". In addition to the contribution to the research area, a proposal to include an insomnia assessment instrument(s) as diagnostic indicators in the NANDA-I taxonomy is planned. It should be noted the low volume of publications of scope review protocols. This protocol has been registered with the Open Science Framework under DOI 10.17605/OSF.IO/8MRPG.
\end{abstract}

Keywords: Evidence-based nursing; Nursing process; Sleep initiation and maintenance disorders; Surveys and questionnaires.

\section{Resumo}

A insônia é um dos principais distúrbios do sono, afetando diferentes grupos etários, influenciando a capacidade do indivíduo de realizar atividades de vida diária e, em última análise, diminuindo sua qualidade de vida. Esta revisão objetiva identificar instrumentos aplicados para o diagnóstico de insônia em ambientes clínicos e de pesquisa para apoiar o processo de enfermagem e a tomada de decisão. Esta revisão tem como base na estrutura de revisão de escopo proposta por Peters et al. (2020). A estratégia de pesquisa delineada visa encontrar estudos publicados na base 
de dados eletrônica CINAHL (EBSCOhost), Portais Scopus, PubMed e WoS. A literatura cinzenta será acessada por meio de busca gratuita no Google e Google Scholar, Repositório de Teses da CAPES, Organizations Associação Brasileira do Sono e World Sleep Society. Espera-se que esta revisão de escopo auxilie os enfermeiros no processo de raciocínio clínico para a identificação do Diagnóstico de Enfermagem "insônia". Para além do contributo para a área de investigação, projeta-se uma proposta à taxonomia NANDA-I de inserção de instrumento(s) para avaliação como indicadores diagnósticos. Ressalta-se o baixo volume de publicações de protocolos de revisão de escopo. Este protocolo foi registrado no Open Science Framework sob DOI 10.17605/OSF.IO/8MRPG.

Palavras-chave: Enfermagem baseada em evidências; Processo de enfermagem; Distúrbios do início e da manutenção do sono; Inquéritos e questionários.

\section{Resumen}

El insomnio es uno de los principales trastornos del sueño, afecta a diferentes grupos de edad, influye en la capacidad del individuo para realizar actividades de la vida diaria y, en última instancia, disminuye su calidad de vida. Esta revisión tiene como objetivo identificar instrumentos aplicados para el diagnóstico del insomnio en entornos clínicos y de investigación para apoyar el proceso de enfermería y la toma de decisiones. Esta revisión se basa en la revisión del alcance propuesto por Peters et al. (2020). La estrategia de investigación planteada tiene como objetivo encontrar estudios publicados en la base de datos electrónica CINAHL (EBSCOhost), Scopus Portals, PubMed y WoS. Se accederá a la literatura gris a través de una búsqueda gratuita en Google y Google Scholar, el repositorio de tesis CAPES, las organizaciones de la Asociación Brasileña del Sueño y la Sociedad Mundial del Sueño. Se espera que esta revisión del alcance ayude a las enfermeras en el proceso de razonamiento clínico para la identificación del Diagnóstico de Enfermería "insomnio". Además del aporte al área de investigación, si planeas una propuesta a la taxonomía NANDA-I para la inserción de instrumento(s) de evaluación como indicadores diagnósticos. Cabe señalar el bajo volumen de publicaciones de protocolos de revisión del alcance. Este protocolo fue registrado en Open Science Framework bajo DOI 10.17605/OSF.IO/8MRPG.

Palabras clave: Enfermería basada en la evidencia; Proceso de enfermería; Trastornos del inicio y del mantenimiento del sueño; Encuestas y cuestionarios.

\section{Introduction}

Insomnia is one of the major sleep disorders, observed across different age groups (Alqudah et al., 2019; Altena et al., 2017). The term sleep disorder refers to conditions affecting the quality, timing or duration of sleep and influence a person's ability to perform routine activities properly. These disorders can contribute to other medical problems and some can also be symptoms of underlying mental health problems (Duncan, \& Sheppard, 2019; Grima, Bei, \& Mansfield, 2019; Zdanowicz et al, 2020).

The $3^{\text {rd }}$ edition of the International Classification of Sleep Disorders (ICSD-III) (2014) revised by the American Academy of Sleep Medicine (AASM), in which is divided into seven major categories, defines insomnia as difficulty in initiating or maintaining sleep; and a decrease in its duration and quality, which occurs despite the opportunity and adequate circumstances for sleeping, associated with dysfunctions during the day. Insomnia is subdivided into Chronic Insomnia Disorder (that occur at least three times a week and persist for the last 3 months), Short-Term Insomnia Disorder (insomnia that have been experienced within three months), Other Insomnia Disorder (difficulty in initiating or maintaining sleep that does not meet the criteria of chronic insomnia or short-term insomnia disorder).

The American Psychiatric Association (APA) (2013) uses the term chronic insomnia disorder (code F51.01 by the International Disease Code-10-CM), in the Sleep-Wake Disorders group, according to the Diagnostic and Statistical Manual of Mental Disorders, 5 $5^{\text {th }}$ Edition, (DSM-5). The diagnostic criteria are: difficulty initiating or maintaining sleep, the latter characterized by frequent awakenings or difficulty in returning to sleep after awakening. It is also characterized by waking up before the usual time with an inability to return to sleep, emphasizing the duration of symptoms and number of episodes.

Insomniacs often experience tiredness or fatigue upon awakening, inability to concentrate and frequent daytime naps, resulting in poor quality of life (Bollu \& Kaur, 2019; Chevance et al., 2020). Depressive symptoms, depression diagnoses (Difrancesco et al., 2019; Silva et al, 2020), and bidirectional relationship between anxiety and mood regulation are observed in patients with insomnia (Tubbs et al, 2020). Futhermore, a potential genetic correlation between insomnia and coronary 
artery disease has been reported (Lane et al., 2019). These findings highlight the importance of investigating insomnia with accurate assessment tools and instruments.

Insomnia results in significant distress in different areas of the individual's life, such as academic (Xie et al., 2017) and social (Bruni et al., 2017), and can last for more than 2 years (Wilson et al., 2019). It can be classified as initial (difficulty starting the sleep period), intermediate (waking up during the night and having difficulty falling asleep), and terminal (unlike the previous one, waking up is very early) (APA, 2013). In the elderly, insomnia is the most significant sleep disorder and its natural reduction in sleep duration can generate anxiety and worsen insomnia symptoms (Patel et al, 2018; Gulia \& Kumar, 2018). Therefore, the participation of the multidisciplinary team in the evaluation process is essential (Molassiotis et al., 2020).

The $11^{\text {th }}$ edition of the NANDA-I Taxonomy (2018-2020) propose the Nursing Diagnosis (ND) "Insomnia" (code 00095) as: "A disruption in amount and quality of sleep that impairs functioning". One of the diagnostic indicators that constitute this ND is Defining Characteristics, that include: alteration in affect; alteration in concentration; alteration in mood; alteration in sleep pattern; compromised health status; decrease in quality of life; difficulty initiating sleep; difficulty maintaining sleep state; dissatisfaction with sleep; early awakening; increase in absenteeism; increase in accidents; insufficient energy; nonrestorative sleep pattern; sleep disturbance producing next-day consequences. The other diagnostic indicators are: Related Factors and Associated Conditions (Herdman \& Kamitsuru, 2017, p. 253).

Diagnostic indicators assist in the adequate assessment, documentation and clinical reasoning that support the diagnostic judgment. Thus, nurses must distinguish the diagnostic indicators to classify the ND "insomnia" and develop the care plan. Besides, diagnostic indicators promote better planning of expected outcomes and interventions that meet the needs of the individual (Brinati et al., 2020; Passarelles et al., 2020).

The use of scales and instruments can assist nurses in diagnostic reasoning in clinical practice (Huang et al, 2020; Schroeder et al., 2021) evaluate response to treatments (Lam \& Macina, 2017), and promote safe evidence-based assistance in different care environments (Vieira et al., 2020). Instruments and scales can be applied by nurses in different contexts and groups, as in the assessment of sleep patterns in health students (Garcia et al., 2019), pathologies associated with overweight (Fusco et al., 2020), assessment of quality of life in oncological individuals (Salvetti et al., 2020) and evaluation of the health of nurses working in psychiatric institutions (Sousa et al., 2020).

Instruments are useful in the assessment of sleep quality, identification of the severity of disorders and diagnosis of insomnia (Riemann et al., 2017). Self-report instruments are usefull to assess sleep quality and other sleep patterns (Rudman et al, 2020), assess the severity of sleep disorders, as insomnia, in different populations and settings (Adell et al., 2020). Besides, these reliable tools are low-cost, fast and user-friendly (Costa et al., 2020).

Populations that benefit from sleep assessment via instruments and scales include women who underwent chemotherapy (Mejía-Rojas et al., 2020), older adults with cognitive impairment (Bademli et al., 2018), depression (Okajima et al., 2020), chronic pain (Dragioti et al., 2018), schizophrenia (Robertson et al, 2019), Coronavirus (COVID-19) related to psychiatric problems (Hao et al., 2020), obstructive sleep apnea (Drakou et al., 2021), institutionalized and noninstitutionalized older adults (Silva et al., 2020), and children and adolescents with high screen media use (Hisler et al., 2020) and other different contexts (Zhou et al., 2020). Among the instruments to assess insomnia, some were applied by nurses (Sagherian et al., 2020; Tselebis et al., 2020) but research is still evolving. Therefore, it is important to identify the instruments, and know them, to assess insomnia.

In view of these facts, and given the complexity of the characteristics of insomnia, the goal of this scoping review protocol is to identify instruments for assessment and diagnosis of insomnia for nurses. 


\section{Methodology}

Also named as "scoping studies" and "mapping studies" (Morris et al., 2016), the scoping review protocols assist in structuring research and selecting studies (Silveira et al., 2020). Some objectives of scoping review are mapping primary studies or review studies, seeking to synthesize the evidence to answer questions related to a specific phenomenon or set of phenomena (Peterson et al., 2017), resume and disseminate findings researches, identify research gaps in the existing literature (Morris et al., 2016), guide health care practice and decision-making in health (Oliveira et al., 2018), in addition to identifying the types of evidence and the way research is conducted on a given topic (Munn et al., 2018). This scoping review protocol has been registered in Open Science Framework (OSF) Registries under the DOI 10.17605/OSF.IO/8MRPG, (osf.io/8mrpg) (Szpalher et al., 2021) and will be conducted according to rigor methodology proposed in the Manual for evidence synthesis by Joanna Briggs Institute (JBI) for Scoping Reviews - 2020 version (Peters et al., 2020).

The Preferred Reporting Items for Systematic Reviews and Meta-Analysis: Extension for Scoping Review (PRISMAScR) Checklist (Tricco et al., 2018) will be used to detail the flow, by selecting the source and presenting the evidence, according to the JBI (Peters et al., 2020). Seeking to offer a straight forward process, with clarity and rigor in the evaluation (Finn et al., 2021), the scoping review methodology based on scoping review framework will be used, and its steps of scoping review process proposed by Peters et al. (2015), are demonstrated below:

\section{Stage 1: Defining and aligning the objectives and question}

This scoping review aims to map instruments applied to diagnose insomnia to provide strategies to guide nurses' decision-making in the diagnostic process. The research questions for this review is: What are the instruments and scales for the assessment and diagnosis of insomnia in nursing practice?

\section{Stage 2: Developing and aligning the inclusion criteria with the objectives and questions}

The key elements of population, concept, context (PCC) mnemonic (Peters et al., 2020). will be used to develop, refine inclusion and exclusion criteria and construct a clear title for this scoping review.

Population - Studies examining children, young, adults, elderly, male and female, without geographical delimitation, age group, related or previous diseases, or language or year will be included in this review. Studies that approach evaluations performed by health professionals, such as nurses, doctors, psychologists and others.

Concept - The concept of interest is: instruments assessing insomnia. The diagnostic criteria for insomnia will be based on the fifth edition of the Diagnostic and Statistical Manual of Mental Disorders (DSM-5 ${ }^{\circledR}$ ) of the American Psychiatric Association (APA), the third edition of the International Classification of Sleep Disorders (ICSD-III) of the American Academy of Sleep Medicine (AASM) and $11^{\mathrm{a}}$ edition of the NANDA-I nursing Taxonomy - 2018-2020.

Context - Studies addressing the use of instruments and scales in the clinical or research areas, published in English, Portuguese, French, and Spanish. Validation studies of instruments that assess insomnia will also be included, regardless of the author's validation process. Studies using scales and tools that have not been validated will be excluded from the sample.

Stage 3: Describing the planned approach to evidence searching, selection, data extraction, and presentation of the evidence

Quantitative and qualitative studies (for example, randomized studies, case study, observational and others) will be included in the review along with secondary studies (literature reviews, umbrella, systematic with and without meta-analysis) and gray literature (doctoral thesis, master's dissertations, opinion texts, reports, Guidelines, Comments and Congress Proceedings). 
Studies published in the electronic databases Cumulative Index of Nursing and Allied Health Literature (CINAHL complete via EBSCOhost), Scopus, PubMed and Web of Science (WoS) Portals will be included. Unpublished literature will be accessed through free search via Google and Google Scholar, Thesis Bank of the Coordination for the Improvement of Higher Education Personnel (CAPES), and publications on the Brazilian Sleep Association and World Sleep Society websites.

The studies will be evaluated in Portuguese, French, English and Spanish. The authors will incorporate keywords and terms from findings in the literature in addition to the proposed search strategies. A date limit for publication will not be adopted for the search and selection of studies, as we understand that the instruments have no expiration date and can potentially be useful regardless of the date of publication.

The search will encompass three stages (Peters et al., 2020). Initially, we will perform a limited search on PubMed Portal and CINAHL Base (via EBSCO) to analyze the titles, abstracts and indexing terms of the retrieved articles. Then, a search with the identified keywords will be performed in the Databases and Portals included. Finally, reference list of the identified studies will be analyzed to find additional sources to be included in scoping review.

The search strategy used in the pilot search is presented in Table 1, organized with the support of a Librarian with experience in academic research in University and applied on March 08, 2021. The same strategy will be adopted in other databases. The search on the Organizations' webpages mentioned will be free, without the adoption of a search strategy and without time limits.

Table 1. Search strategy in PubMed.

\begin{tabular}{ll}
\hline Keyword searched & Database used \\
\hline ("Sleep Initiation and Maintenance Disorders"[MeSH Terms] OR "Insomnia"[Title]) AND & PubMed Portal \\
("surveys and questionnaires"[MeSH Terms] OR "scale"[Title] OR "test"[Title] OR & \\
"assessment"[Title] OR "measure"[Title] OR "instrument"[Title] OR "index"[Title] AND & \\
Nurs*[Title/Abstract]) & \\
\hline
\end{tabular}

Source: Own authorship.

\section{Stage 4: Searching for the evidence}

A preliminary search was performed between December 2020 and February 2021 in the PROSPERO register, The Database of Abstracts of Reviews of Effects (DARE), JBI Database of Systematic Reviews and Implementation Reports, Cochrane Database of Systematic Reviews, and Google Scholar free search. Search strategies specifically developed and adapted to each base were used, as recommended by JBI Manual (Peters et al., 2020).

The specific strategies for each base involved research based on Health Sciences Descriptors (DeCS) and Medical Subject Headings (MeSH) and in related free terms, combined with the Boolean operators AND and OR. There was no time or language delimitation, restriction filters in this initial search. The results were analyzed by titles and abstracts as needed.

We observed the absence of scoping review and systematic review, with or without meta-analysis, addressing this study's proposed theme. It is noteworthy existing studies focus on insomnia-related pharmacology, economic costs, prevalence comparison, and effectiveness studies, in progress or completed. We also found studies focused on cognitive-behavioral or music therapies for insomnia. Thus, emphasizing the relevance of the research proposed in this protocol.

\section{Stage 5: Selecting the evidence}

Analysis of the titles/abstracts will be performed, and studies will be selected for a full reading by two independent reviewers. Articles that do not meet the inclusion criteria will be presented in the scoping review. Disagreements regarding the reviewer's selection of studies will be solved by a third reviewer with sleep medicine expertise. New articles will be retrieved 
from the selected articles for a final analysis.

After this analysis, references will be searched in the selected articles in order to identify other important sources. The sample size presented in the articles is not criteria of inclusão ou exclusion for selecting the studies.

\section{Stage 6: Extracting the evidence}

An instrument for data collection a "blind" screening process, prepared by the reviewers, will be used as indicated in the JBI Manual (Table 2):

Table 2. Detailing of scope review and data collection.

Search Detail: Tools and scales to assess insomnia

\section{Detailing of scoping review}

Review Objective: Map existing evidence about instruments and scales stratification of insomnia.

Research Question: What are the instruments and scales for the assessment and diagnosis of insomnia in nursing practice?

\section{Inclusion Criteria}

Population: Individuals from both genders and all age groups, evaluations performed by health professionals.

Concept: Instruments and scales that assess aspects related to insomnia.

Context: Clinical and research settings, without geographical delimitation, in addition to instrument validation studies.

Year: No limitation

In: PubMed, CINAHL via EBSCOhost, Scopus, WoS and Free search.

\section{Characteristics of the selected study after reading in full}

Authors:

Year and Periodic:

Title:

Design Study:

Language:

Name of instrument/scale:

Did you need to contact the authors? By which email?

Present aspects related to insomnia:

This instrument is intended for children/adolescents/adults/elderly:

Did the study attach the instrument/scale? If so, attach it here. If not, search the free internet for a better evaluation, and answer the question above.

Source: Own authorship.

\section{Stage 7: Analysis of the evidence}

Our goal is to identify aspects related to the assessment and diagnosis of insomnia. Authors of the studies will be contacted via email for clarification or additional information during the process of this review as needed. The contact will be made by one of the authors. Data extracted from the standardized instrument (Table 2) will be subjected to qualitative content analysis, in a descriptive way, and categorization of findings.

\section{Stage 8: Presentation of the results}

Zotero ${ }^{\circledR}$ software (United States) will be used to organize results and remove duplicates. The Rayyan (Qatar Computing Research Institute, Doha, Qatar - QCRI ${ }^{\circledR}$ ) software for systematic reviews (Ouzzani et al, 2016) will be used to ensure a "blind" screening process and minimize bias. The PRISMA-ScR flowchart for depicts the flow of information through the different phases will be presented in the scoping review. The results will be presented in graphs and tables.

Data will be categorized and summarized as described in Table 3: 
Table 3. Presentation of data for a scoping review.
Numbers of publications
Total number of sources of evidence and number of publications each year
Types of studies
Randomized controlled trials; Non-randomized controlled trials; Quasi-experimental; Before-and-after; Prospective cohort; Retrospective cohort; Case-control; Cross-sectional; Other quantitative; Qualitative studies.
Population
Children; adults; elderly; Not applicable
Health Care Profissional
Nurse; Doctor; Therapist; Other
Validation Process
Just mention the validation process adopted
Source: Own authorship.

\section{Stage 9: Summarizing the evidence concerning the purpose of the review, making conclusions and noting any implications of the findings}

Final data will be summarized after an appraisal or a third reviewer and consensus of all reviewers. Results will assist nurses in choosing the appropriate insturment for assessment and diagnose of insomnia. Summarize of evidence will highlight the peculiarities of these instruments and in disseminating the evidence available for research and health practice.

The presentation of the data will, prior to the publication of the scoping review, by consensus of a third reviewer for final agreement. Our goal is to complete this scoping review in the period of 6 months, understanding that such a period of time is reasonable for complying with the proposal.

\section{Results and Discussion}

The exercise of clinical reasoning aids diagnostic accuracy and enables adequate targeting of nursing interventions to achieve better health goals (Freitas \& Conceição, 2018). The synthesis of knowledge, proposed in this protocol will facilitate the nurse's clinical judgment (Lourenço et al, 2020), and the decision-making regarding the instrument or scale for insomnia.

This scoping review will assist nurses in the clinical reasoning process for identifying ND "insomnia". In- and out-ofhospital environments, as home care, can be opportune places to observe insomnia patterns for nurses. The accurate look, aided by instruments, can promote objectivity in the evaluation and decision making, where adequate sleep can influence the quality of life.

The authors' clinical experience with insomnia confirmed the need for a review of instruments that address aspects related to insomnia. This is a scoping review study, so it did not require the patient or general public involvement. As a review of literature, there are no study participants in active enrollment for this study. If the review presents ethical issues resulting from the sources of evidence, these will be discussed in the results.

This is the first comprehensive review to synthesize evidence of useful tools for insomnia assessment by nurses. The review of the literature will be conducted with support from a research librarian with expertise in scoping review search in eight databases.

Since it is a scoping review, the quality of evidence, effectiveness of interventions/therapies, and risk of bias will not be assessed. Beyond this, will be selected only publications written in Portuguese, English, Spanish and French due the shortage of studies in other languages.

\section{Final Considerations}

Given the need to perform this review to guide the nursing process in the diagnosis of insomnia, this study may also contribute to the evaluation of nurses who work in the investigation and treatment of individuals with insomnia symptoms, 
given the high prevalence of this condition, regardless of age, socioeconomic status, gender and geographic location.

After the mentioned search, the low volume of publications of scope reviews is emphasized, even with the encouragement of scientific entities and Organizations that provide guidance about reviews on the importance of conducting their studies.

Aiming to disseminate the knowledge attributed to this study, the results will be published in a peer-reviewed journal and will be presented at Congresses or health scientific events. This research received no specific grant from any funding agency in public, commercial or not-for-profit sectors.

In addition to the contribution to the research area, a proposal is planned for the NANDA-I Taxonomy to include an insomnia assessment instrument(s) as diagnostic indicators for the identification of ND. This scoping review sought to promote screening and diagnosis of insomnia in healthcare and research practices for nurses. Results will contribute to further develop the Defining Characteristics and Associated Factors of the ND "insomnia" in upcoming versions of the NANDA-I, with potential benefits for the Nursing Interventions (NIC) and of Outcomes Nursing (NOC) worldwide.

\section{Acknowledgments}

This study is an excerpt from the master's thesis of one of the authors and is supported by Adriana Souza Szpalher, that thanks the master thesis committee: Dr Priscilla Alfradique de Souza - Postgraduate Program in Nursing at the Federal University of the State of Rio de Janeiro (PPGENF-UNIRIO); Dr Rosane Barreto Cardoso - State University of Rio de Janeiro (UERJ) and Dr Carleara Weiss - University at Buffalo: The State University of New York in the United States (SUNY Buffalo).

\section{References}

Adell, M. D. B., Andrés, E. B., Barrachina, L. G., Graullera, G. C., Aznar, G. P., Urendez, A. M., Marmaneu, M. A. M., Lázaro, A. M., \& Selles, M. D. F. (2020). Psychometric evaluation of the Freedman questionnaire to assess sleep in critical patients. Medicina Intensiva (English Edition), 44(6), 344-350. https://doi.org/10.1016/j.medine.2019.04.009

Alqudah, M., Balousha, S. A. M., Al-Shboul, O., Al-Dwairi, A., Alfaqih, M. A., \& Alzoubi, K. H. (2019). Insomnia among Medical and Paramedical Students in Jordan: Impact on Academic Performance. BioMed Research International, 2019, 1-7. https://doi.org/10.1155/2019/7136906

Altena, E., Chen, I. Y., Daviaux, Y., Ivers, H., Philip, P., \& Morin, C. M. (2017). How Hyperarousal and Sleep Reactivity Are Represented in Different Adult Age Groups: Results from a Large Cohort Study on Insomnia. Brain Sciences, 7(4):41. https://doi.org/10.3390/brainsci7040041

American Academy of Sleep Medicine. International classification of Sleep Disorders. (3rd ed.). American Academy of Sleep Medicine, Darien, IL, 2014

American Psychiatric Association. Diagnostic and Statistical Manual of Mental Disorders. (5th ed.). American Psychiatric Publishing, Arlington, VA, 2013

Bademli, K., Lok, N., Canbaz, M., \& Lok, S. (2019). Effects of Physical Activity Program on cognitive function and sleep quality in elderly with mild cognitive impairment: A randomized controlled trial. Perspect Psychiatr Care, 55: 401-408. https://doi.org/10.1111/ppc.12324

Bollu, P. C., \& Kaur, H. (2019). Sleep Medicine: Insomnia and Sleep. Missouri Medicine, 116(1), 68-75. https://www.ncbi.nlm.nih.gov/pmc/ar ticles/PMC6390785/

Brinati, L. M., Fátima Januário, C., Balbino, P. C., Gonçalves Rezende Macieira, T., Cardoso, S. A., Moreira, T. R., \& Salgado, P. O. (2020). Incidence and Prediction of Unstable Blood Glucose Level among Critically Ill Patients: A Cohort Study. International Journal of Nursing Knowledge, $2047-3095.12299$. https://doi.org/10.1111/2047-3095.12299

Bruni, O., Angriman, M., Calisti, F., Comandini, A., Esposito, G., Cortese, S., \& Ferri, R. (2018). Practitioner Review: Treatment of chronic insomnia in children and adolescents with neurodevelopmental disabilities. Journal of Child Psychology and Psychiatry, 59(5), 489-508. https://doi.org/10.1111/jcpp.12812

Chevance, A., Gourion, D., Hoertel, N., Llorca, P.-M., Thomas, P., Bocher, R., Moro, M.-R., Laprévote, V., Benyamina, A., Fossati, P., Masson, M., Leaune, E., Leboyer, M., \& Gaillard, R. (2020). Assurer les soins aux patients souffrant de troubles psychiques en France pendant 1'épidémie à SARS-CoV-2. L'Encéphale, 46(3), S3-S13. https://doi.org/10.1016/j.encep.2020.03.001

Costa, Z. M. S. S., Pinto, R. D. M. C., Mendonça, T. M. S., \& Silva, C. H. M. (2020). Validação brasileira dos bancos de iten s Distúrbio do Sono e Distúrbio da Vigília do Patient-Reported Outcomes Measurement Information System (PROMIS). Cadernos de Saúde Pública, 36(6), e00228519. Cad. Saúde Pública (Online); 36(6): e00228519. https://doi.org/10.1590/0102-311x00228519

Difrancesco, S., Lamers, F., Riese, H., Merikangas, K. R., Beekman, A. T. F., Hemert, A. M., Schoevers, R. A., \& Penninx, B. W. J. H. (2019). Sleep, circadian rhythm, and physical activity patterns in depressive and anxiety disorders: A 2-week ambulatory assessment study. Depression and Anxiety, 36(10), 975-986. 
https://doi.org/10.1002/da.22949

Dragioti, E., Bernfort, L., Larsson, B., Gerdle, B., \& Levin, L. Å. (2018). Association of insomnia severity with well-being, quality of life and health care costs: A cross-sectional study in older adults with chronic pain (PainS65+). European Journal of Pain, 22(2), 414-425. https://doi.org/10.1002/ejp.1130

Drakou, T., Steiropoulos, P., Saroglou, M., Georgopoulou, A., Kazis, D., Papagiannopoulos, S., Porpodis, K., \& Tryfon, S. (2021). The presence of insomnia and depression contributes to the acceptance of an initial treatment trial of continuous positive airway pressure therapy in patients with obstructive sleep apnea. Sleep and Breathing. https://doi.org/10.1007/s11325-020-02266-z

Duncan, C., \& Sheppard, K. (2019). Implications and recommendations for addressing insomnia disorder. The Nurse Practitioner, 44(1), 19-25. https://doi.org/10.1097/01.NPR.0000550249.19773.87

Finn, M., Gilmore, B., Sheaf, G., \& Vallières, F. (2021). What do we mean by individual capacity strengthening for primary health care in low- and middleincome countries? A systematic scoping review to improve conceptual clarity. Human Resources for Health, 19(1), 5. https://doi.org/10.1186/s12960-020$00547-\mathrm{y}$

Freitas, N. C., \& Conceição, A. P. (2018). Acurácia dos diagnósticos de enfermagem de uma instituição de cardiologia. Revista de Enfermagem UFPE on Line, 12(10), 2727. https://doi.org/10.5205/1981-8963-v12i10a234595p2727-2736-2018

Fusco, S. de F. B., Amancio, S. C. P., Pancieri, A. P., Alves, M. V. M. F. F., Spiri, W. C., \& Braga, E. M. (2020). Ansiedade, qualidade do sono e compulsão alimentar em adultos com sobrepeso ou obesidade. Revista da Escola de Enfermagem da USP, 54, e03656. https://doi.org/10.1590/s1980-220x2019013903656

Garcia, A., Louro, T., Santiago, L.C., Silva, R.C., Barbosa, M.T., Silva, V.F., Machado, D.A., \& Silva, C.R. (2019). Evaluation of sleep quality of postgraduation nursing students. Journal of Nursing Ufpe Online, 13, 1444-1453. https://doi.org/10.5205/1981-8963-v13i05a239167p1444-1453-2019

Grima, N. A., Bei, B., \& Mansfield, D. (2019). Insomnia theory and assessment. Australian Journal of General Practice, 48(4), 193-197. https://doi.org/10.31128/AJGP-12-18-4780

Gulia, K. K., \& Kumar, V. M. (2018). Sleep disorders in the elderly: A growing challenge: Sleep in elderly. Psychogeriatrics, 18(3), 155-165. https://doi.org/10.1111/psyg.12319

Hao, F., Tan, W., Jiang, L., Zhang, L., Zhao, X., Zou, Y., Hu, Y., Luo, X., Jiang, X., McIntyre, R. S., Tran, B., Sun, J., Zhang, Z., Ho, R., Ho, C., \& Tam, W. (2020). Do psychiatric patients experience more psychiatric symptoms during COVID-19 pandemic and lockdown? A case-control study with service and research implications for immunopsychiatry. Brain, behavior, and immunity, 87, 100-106. https://doi.org/10.1016/j.bbi.2020.04.069

Herdman, T. H., \& Kamitsuru, S. NANDA International Nursing Diagnoses: Definitions classification, 2018-2020. Theime; 2017.

Hisler, G. C., Hasler, B. P., Franzen, P. L., Clark, D. B., \& Twenge, J. M. (2020). Screen media use and sleep disturbance sy mptom severity in children. Sleep Health, 6(6), 731-742. https://doi.org/10.1016/j.sleh.2020.07.002

Huang, J., Yang, L., Qi, H., Zhu, Y., \& Zhang, M. (2020). Psychometric properties of the Chinese version of the End-of-Life Decision-Making and Staff Stress Questionnaire. International Journal of Clinical and Health Psychology, 20(3), 271-281. https://doi.org/10.1016/j.ijchp.2020.07.001

Lam, S., \& Macina, L. O. (2017). Therapy Update for Insomnia in the Elderly. The Consultant Pharmacist, 32(10), 610-622. https://doi.org/10.4140/TCP.n.2017.610

Lane, J. M., Jones, S. E., Dashti, H. S., Wood, A. R., Aragam, K. G., van Hees, V. T., Strand, L. B., Winsvold, B. S., Wang, H., Bowden, J., Song, Y., Patel, K., Anderson, S. G., Beaumont, R. N., Bechtold, D. A., Cade, B. E., Haas, M., Kathiresan, S., Little, M. A., Luik, A. I., ... Saxen a, R. (2019). Biological and clinical insights from genetics of insomnia symptoms. Nature genetics, 51(3), 387-393. https://doi.org/10.1038/s41588-019-0361-7

Lourenço, T. M. G., Abreu-Figueiredo, R. M. S., \& Sá, L. O. de. (2020). Review of nursing diagnosis validation studies: Caregiver role strain. Revista Gaúcha de Enfermagem, 41, e20190370. https://doi.org/10.1590/1983-1447.2020.20190370

Mejía-Rojas, M. E., Contreras-Rengifo, A., \& Hernández-Carrillo, M. (2020). Calidad de vida en mujeres con cáncer de mama sometidas a quimioterapia en Cali, Colombia. Biomédica, 40(2), 349-361. https://doi.org/10.7705/biomedica.4971

Molassiotis, A., Fraser, A., Culligan, M., Labuc, P., Csaba, D. L., \& Charalambous, A. (2020) Nursing and Allied Health Research Priorities in the Care of Patients With Thoracic Malignancies: An International Cross-Sectional Survey. Frontiers in Oncology. 10:591799. 10.3389/fonc.2020.591799

Morris, M., Boruff, J. T., \& Gore, G. C. (2016). Scoping reviews: establishing the role of the librarian. Journal of the Medical Library Association: JMLA, 104(4), 346-354. https://doi.org/10.3163/1536-5050.104.4.020

Munn, Z., Peters, M. D. J., Stern, C., Tufanaru, C., McArthur, A., \& Aromataris, E. (2018). Systematic review or scoping review? Guidance for authors when choosing between a systematic or scoping review approach. BMC Medicine Research Methodology 18, 143. https://doi.org/10.1186/s12874-018-0611-x

Okajima, I., Miyamoto, T., Ubara, A., Omichi, C., Matsuda, A., Sumi, Y., Matsuo, M., Ito, K., \& Kadotani, H. (2020). Evaluation of Severity Levels of the Athens Insomnia Scale Based on the Criterion of Insomnia Severity Index. International journal of environmental research and public health, 17(23), 8789. https://doi.org/10.3390/ijerph17238789

Oliveira, A., Graveto, J., Osório, N., Costa, P., Oliveira, V., Costa, F., \& Parreira, P. (2018). Potential for contamination of tourniquets during peripheral venipuncture: A scoping review protocol. Revista de Enfermagem Referência, IV Série(17), 143-148. https://doi.org/10.12707/RIV17104172

Ouzzani, M., Hammady, H., Fedorowicz, Z., \& Elmagarmid, A. (2016). Rayyan - a web and mobile app for systematic reviews. Systematic Reviews 5, 210. https://doi.org/10.1186/s13643-016-0384-4

Passarelles, D. M. A., Santana, R. F., Almeida, A. R., Silva, D. E. S., \& Pereira, S. K. (2020). Diagnóstico de enfermagem síndrome de terminalidade em 
idosos com demência avançada: Mapeamento cruzado. Revista Enfermagem UERJ, 28, e49901. https://doi.org/10.12957/reuerj.2020.49901

Patel, D., Steinberg, J., \& Patel, P. (2018). Insomnia in the Elderly: A Review. Journal of Clinical Sleep Medicine, 14(06), 1017-1024. https://doi.org/10.5664/jesm.7

Peters, M. D. J., Godfrey, C. M., Khalil, H., McInerney, P., Parker, D., \& Soares, C. B. (2015). Guidance for conducting systematic scoping reviews. International Journal of Evidence-Based Healthcare, 13(3), 141-146. https://doi.org/10.1097/XEB.0000000000000050

Peters, M. D. J., Godfrey, C., McInerney, P., Munn, Z., Tricco, A. C., \& Khalil, H. Chapter 11: Scoping Reviews (2020 version). In: Aromataris E, Munn Z (Editors). JBI Manual for Evidence Synthesis, JBI. https://doi.org/10.46658/JBIMES-20-12

Peterson, J., Pearce, P. F., Ferguson, L. A., \& Langford, C. A. (2017). Understanding scoping reviews: Definition, purpose, and process. Journal of the American Association of Nurse Practitioners, 29(1), 12-16. https://doi.org/10.1002/2327-6924.12380

Riemann, D., Baglioni, C., Bassetti, C., Bjorvatn, B., Dolenc Groselj, L., Ellis, J. G., Espie, C. A., Garcia-Borreguero, D., Gjerstad, M., Gonçalves, M., Hertenstein, E., Jansson-Fröjmark, M., Jennum, P. J., Leger, D., Nissen, C., Parrino, L., Paunio, T., Pevernagie, D., Verbraecken, J., Weeß, H. G., \& Spiegelhalder, K. (2017). European guideline for the diagnosis and treatment of insomnia. Journal of sleep research, 26(6), 675-700. https://doi.org/10.1111/jsr.12594

Robertson, I., Cheung, A., \& Fan, X. (2019). Insomnia in patients with schizophrenia: Current understanding and treatment options. Progress in NeuroPsychopharmacology and Biological Psychiatry, 92, 235-242. https://doi.org/10.1016/j.pnpbp.2019.01.016

Rudman, A., Arborelius, L., Dahlgren, A., Finnes, A., \& Gustavsson, P. (2020). Consequences of early career nurse burnout: A prospective long-term follow-up on cognitive functions, depressive symptoms, and insomnia. EClinicalMedicine, 27, 100565. https://doi.org/10.1016/j.eclinm.2020.100565

Sagherian, K., Steege, L. M., Cobb, S. J., \& Cho, H. (2020). Insomnia, fatigue and psychosocial well-being during COVID-19 pandemic: A cross-sectional survey of hospital nursing staff in the United States. Journal of Clinical Nursing, jocn.15566. https://doi.org/10.1111/jocn.15566

Salvetti, M. G., Machado, C. S. P., Donato, S. C. T., \& Silva, A. M. (2020). Prevalence of symptoms and quality of life of cancer patients. Revista Brasileira de Enfermagem, 73(2), e20180287. https://doi.org/10.1590/0034-7167-2018-0287

Schroeder, S. K., Samady, W., Kolaitis, I. N., Smith, C. M., Palac, H., Shreffler, L., \& Nevin, M. A. (2021). Comparison of Two Assessment Tools for Hospitalized Subjects With Asthma. Respiratory Care, 66(1), 104-112. https://doi.org/10.4187/respcare.07761

Silva, R. M, Afonso, P., Fonseca, M., \& Teodoro, T. (2020). Comparing sleep quality in institutionalized and non-institutionalized elderly individuals. Aging \& mental health, 24(9), 1452-1458. https://doi.org/10.1080/13607863.2019.1619168

Silveira, L., Barbosa, A. D., Ferreira, M. K., \& Caregnato, S. E. Citação de dados científicos: scoping review. Encontros Bibli: Revista Eletrônica de Biblioteconomia e Ciência da Informação, 25:1-31, 2020. 10.5007/1518-2924.2020.e72153

Sousa, K. H. J. F., Zeitoune, R. C. G., Portela, L. F., Tracera, G. M. P., Moraes, K. G., \& Figueiró, R. F. S. (2020). Factors related to the risk of illness of nursing staff at work in a psychiatric institution. Revista Latino-Americana de Enfermagem, 28, e3235. https://doi.org/10.1590/1518-8345.3454.3235

Szpalher, A. S., de Souza, P. A., Cardoso, R. B., Weiss, C., da Silva, N. C. M., \& da Silva Ramos, L. M. A. (2021). Assessment and diagnosis of insomnia for clinical and research practice: a scoping review protocol. Open Science Framework. https://doi.org/10.17605/OSF.IO/8MRPG

Tricco, A. C., Lillie, E., Zarin, W., O'Brien, K. K., Colquhoun, H., Levac, D., Moher, D., Peters, M., Horsley, T., Weeks, L., Hempel, S., Akl, E. A., Chang, C., McGowan, J., Stewart, L., Hartling, L., Aldcroft, A., Wilson, M. G., Garritty, C., Lewin, S., \& Straus, S. E. (2018). PRISMA Extension for Scoping Reviews (PRISMA-ScR): Checklist and Explanation. Annals of internal medicine, 169(7), 467-473. https://doi.org/10.7326/M18-0850

Tselebis, A., Lekka, D., Sikaras, C., Tsomaka, E., Tassopoulos, A., Ilias, I., Bratis, D., \& Pachi, A. (2020). Insomnia, Perceived Stress, and Family Support among Nursing Staff during the Pandemic Crisis. Healthcare, 8(4), 434. https://doi.org/10.3390/healthcare8040434

Tubbs, A. S., Khader, W., Fernandez, F., \& Grandner, M. A. (2020). The common denominators of sleep, obesity, and psychopathology. Current Opinion in Psychology, 34, 84-88. https://doi.org/10.1016/j.copsyc.2019.11.003

Vieira, T. W., Sakamoto, V. T. M., Moraes, L. C., Blatt, C. R., \& Caregnato, R. C. A. (2020). Validation methods of nursing care protocols: an integrative review. Rev Bras Enferm, 73(Suppl 5):e20200050. doi: http://dx.doi.org/10.1590/0034-7167-2020-0050

Wilson, S., Anderson, K., Baldwin, D., Dijk, D.-J., Espie, A., Espie, C., Gringras, P., Krystal, A., Nutt, D., Selsick, H., \& Sharpley, A. (2019). British Association for Psychopharmacology consensus statement on evidence-based treatment of insomnia, parasomnias and circadian rhythm disorders: An update. Journal of Psychopharmacology, 33(8), 923-947. https://doi.org/10.1177/0269881119855343

Xie, Z., Chen, F., Li, W. A., Geng, X., Li, C., Meng, X., Feng, Y., Liu, W., \& Yu, F. (2017). A review of sleep disorders and melatonin. Neurological Research, 39(6), 559-565. https://doi.org/10.1080/01616412.2017.1315864

Zdanowicz, T., Turowski, K., Celej-Szuster, J., Lorencowicz, R., \& Przychodzka, E. (2020). Insomnia, Sleepiness, and Fatigue Among Polish Nurses. Workplace Health \& Safety, 68(6), 272-278. https://doi.org/10.1177/2165079920901534

Zhou, S.-J., Wang, L.-L., Yang, R., Yang, X.-J., Zhang, L.-G., Guo, Z.-C., Chen, J.-C., Wang, J.-Q., \& Chen, J.-X. (2020). Sleep problems among Chinese adolescents and young adults during the coronavirus-2019 pandemic. Sleep Medicine, 74:39-47. https://doi.org/10.1016/j.sleep.2020.06.001 